\title{
(息)
}

Citation:

Staff, H and Didymus, FF and Backhouse, SH (2020) Dyadic coping in coach-athlete relationships : A grounded theory. Psychology of Sport and Exercise. ISSN 1469-0292 DOI: https://doi.org/10.1016/j.psychsport.2020.101741

Link to Leeds Beckett Repository record:

https://eprints.leedsbeckett.ac.uk/id/eprint/6796/

Document Version:

Article (Accepted Version)

Creative Commons: Attribution-Noncommercial-No Derivative Works 4.0

The aim of the Leeds Beckett Repository is to provide open access to our research, as required by funder policies and permitted by publishers and copyright law.

The Leeds Beckett repository holds a wide range of publications, each of which has been checked for copyright and the relevant embargo period has been applied by the Research Services team.

We operate on a standard take-down policy. If you are the author or publisher of an output and you would like it removed from the repository, please contact us and we will investigate on a case-by-case basis.

Each thesis in the repository has been cleared where necessary by the author for third party copyright. If you would like a thesis to be removed from the repository or believe there is an issue with copyright, please contact us on openaccess@leedsbeckett.ac.uk and we will investigate on a case-by-case basis. 
Running head: DYADIC COPING IN COACH-ATHLETE RELATIONSHIPS

Dyadic coping in coach-athlete relationships: A grounded theory

Helen R. Staff, Faye F. Didymus, and Susan H. Backhouse

Leeds Beckett University, United Kingdom

Author Note

Helen R. Staff, Faye F. Didymus, and Susan H. Backhouse, Carnegie Research Institute, Leeds Beckett University, United Kingdom.

Correspondence concerning this article should be addressed to Helen R. Staff, Carnegie Research Institute, Leeds Beckett University, Headingley Campus, Leeds, LS6 3QS, United Kingdom. Telephone: 44(0)113-812-3246. Email: H.R.Staff@leedsbeckett.ac.uk 


\begin{abstract}
Objectives: The purpose of this study was to make an original contribution to sport psychology literature by offering a substantive grounded theory of dyadic coping in coachathlete relationships. Specifically, this study aimed to capture the development and manifestation of dyadic coping for coaches and athletes operating in individual sports. Design: Using constructionist grounded theory methodology as a guide, a theory of dyadic coping was constructed by the authors, 13 coaches, 15 athletes, and five sport and exercise psychology practitioners.

Method: Theoretical sampling procedures ensured that data collection was directed by the developing theoretical concepts, rather than a set of predefined criteria. We conducted individual interviews $(\mathrm{n}=16)$ with coaches and athletes, and one 90-minute workshop with coaches, athletes, and sport and exercise psychology practitioners. Methodological rigor was enhanced by focusing on credibility, originality, resonance, and usefulness.

Results: The theory proposes that when coaches and athletes appraise a stressor communicated in their dyad as significant and meaningful, they use dyadic coping to protect themselves and their coach-athlete relationships. This process is moderated by a number of personal (e.g., personality), relationship (e.g., length), and organizational (e.g., leadership behaviors) characteristics.

Conclusion: The theory presented here represents a notable shift in thinking away from coping as an individual process and toward coping as an important interpersonal phenomenon. This type of coping can have long-term effects on coaches' and athletes' relationship functioning, well-being, and performance.
\end{abstract}

Keywords: appraisals, interpersonal relationships, high-performance sport, stress 


\section{Dyadic coping in coach-athlete relationships: A grounded theory}

Within the context of high-performance sport, there has been increasing academic interest in the individual coping strategies that athletes' and coaches' use to manage the numerous stressors they encounter (Burlot, Richard, \& Joncheray, 2016; Didymus, 2017). The majority of this research has been guided by transactional stress perspectives, which emphasize that stress resides in the relationship between the person and the environment (Lazarus \& Launier, 1978), and focus on psychological processes such as appraising and coping. Thus, sport psychology researchers have provided an understanding of the individual coping strategies that athletes (e.g., planning, venting emotions, goal withdrawal; Nicholls, Taylor, Carroll, \& Perry, 2016) and coaches (e.g., planning, self-talk, centering; Didymus, 2017) use.

This body of research has been influential in the development of stress literature and, at the same time, there has been increasing interest in the interpersonal relationships in sport (e.g., coach-athlete dyads, Jowett, 2007; athlete-parent dyads, Neely, McHugh, Dunn, \& Holt, 2017) and the influence of these relationships on well-being (Kaye, Frith, \& Vosloo, 2015; Stebbings, Taylor, \& Spray, 2016) and performance (Davis, Appleby, Davis, Wetherell, \& Gustafsson, 2018; Tamminen, Poucher, \& Povilaitis, 2017). Researchers have implied that these relationships create environments in which shared cognitions, interpersonal behaviors, and performance can be nurtured (Jowett, 2007). The interpersonal relationships athletes develop are, therefore, considered key components of their social environment and have the potential to influence stress transactions (Tamminen \& Holt, 2012; Nicholls \& Perry, 2016). Specifically, stress researchers have revealed that the presence of a coach can influence an athlete's appraisals (Nicholls, Levy et al., 2016), coping resources (Staff, Didymus, \& Backhouse, 2017a), and emotions (Thelwell, Wagstaff, Rayner, Chapman, \& Barker, 2017). In light of this research, researchers have begun to speculate that the 
interpersonal relationship in sport may act as a vehicle for interpersonal coping (Didymus, 2017; Neely et al., 2017; Staff et al., 2017a; Tamminen \& Gaudreau, 2014). Such speculations suggest that moving away from investigations that describe the mechanics of these relationships (e.g., Jowett, 2007) or individual coping strategies (Didymus, 2017) and towards a nuanced explanation of coping as an interpersonal phenomenon is warranted.

Although researchers have only just begun to speculate over interpersonal coping in sport, the study of interpersonal coping has grown considerably in recent years in health and relationship psychology (e.g., Lyons, Miller, \& McCarthy, 2016; Rottman et al., 2015). Here, researchers (e.g., Bodenmann, 1995; Lyons, Mickelson, Sullivan, \& Coyne, 1998) have conceptualized interpersonal coping as a dynamic and reciprocal process in which dyads (i.e., close personal relationships between two people) respond to stressors communicated within their relationships and engage jointly in managing the stressor (Bodenmann, 1997, 2005). Guided by the work of Lazarus and colleagues (1984, 1993, 1999), Bodenmann $(1995,1997)$ referred to this process as dyadic coping differing this from individual coping, which identifies an individual's behavioral efforts to deal with internal and external demands that challenge or exceed his or her resources (Lazarus \& Folkman, 1984). However, as knowledge has developed in domains outside of sport, researchers have used various terms to refer to the interpersonal nature of coping. For instance, some refer to collective coping (Kuo, 2012) or communal coping (Lyons et al., 1998) to mean similar things as Bodenmann's dyadic coping. Unfortunately, the lack of consistency in the way that scholars have conceptualized interpersonal coping has stunted the development of knowledge and has created confusion in the work that does exist. Beyond this, the distinction between dyadic coping and alternative levels of support (i.e., social support) continues to limit interpersonal coping research. Thus, researchers (Staff et al., 2017a) have attempted to provide differentiation across these concepts, identifying social support as the unidirectional provision of support, in contrast to 
dyadic coping that involves bidirectional support within interpersonal relationships.

Considering this and the different terms that are available, we use "dyadic coping" to explain the process whereby sport based dyads (e.g., coach-athlete) manage stressors together.

The dynamic and reciprocal process of dyadic coping was reflected in Bodenmann's (1995) Systemic Transactional Model (STM), which was developed to explain interpersonal coping among romantic couples. Specifically, this model frames positive (i.e., common, supportive, delegate, and stress communication) and negative (i.e., hostile, ambivalent, and superficial) dyadic coping as a secondary coping pathway that people engage with when their individual coping efforts, that are detailed in transactional stress theory (Lazarus \& Folkman, 1984), have been exhausted. From this perspective, a dyadic unit is co-created when both individuals frame their coping efforts as an interpersonal process (Donato, Iafrate, Bradbury, \& Scabini, 2012) and, together, expand their coping resources. The STM has provided initial insight into the positive implications of dyadic coping for relationship functioning and personal health (Bergstraesser, Inglin, Hornung, \& Landolt, 2015; Rottmann et al., 2015). Nevertheless, it is not clear if dyadic coping can have negative implications for close personal relationships. Staff, Didymus, \& Backhouse (2017b) suggested that dyadic coping is a double-edged sword, as literature acknowledges negative implications on mental health and quality of life. Understanding more about the implications of dyadic coping, and the role it plays in sporting dyads, would enable researchers, practitioners, and sports organizations to more effectively support stakeholders' well-being (Stebbings et al., 2016) and performance (Davis et al., 2018). It is, however, challenging to study dyadic coping across sporting dyads by applying existing theories (e.g., STM, Bodenmann, 1995) because of the fundamental differences between these relationships and those of a romantic partners where power dynamics are less evident and partners choose to invest in the relationship to fulfil security and intimacy needs (Ainsworth, Blehar, Waters, \& Wall, 1978; Winterheld \& Simpson, 
2011).

Previously two studies have examined dyadic coping in the context of coach-athlete relationships. First, Nicholls and Perry (2016) explored positive coach-athlete relationships as mediators of dyadic coping and a coach's appraisals of stressors. This study reported that effective dyadic coping strategies (e.g., positive dyadic coping; Bodenmann, 1997) enhanced coaches' perceptions of relationship quality. In the second study, Staff et al. (2017a) highlighted antecedents of dyadic coping and showed that dyadic coping contributed to personal and relationship growth. Although these studies revealed that dyadic coping was prevalent in coach-athlete relationships, how dyadic coping manifests and develops in highperformance coach-athlete relationships remains unclear. Given this, and the interdependent nature of this dyad (Jowett, 2007), generating an initial theoretical understanding of dyadic coping in coach-athlete dyads is an important first step to progress sport psychology knowledge. Specifically, it would provide an initial framework for researchers wishing to explore coach-athlete relationships or other sporting dyads to build on (Flick, 2018). The purpose of this study was, therefore, to develop a substantive theory of dyadic coping in coach-athlete relationships. Specifically, we aimed to capture the manifestation and development of dyadic coping in coach-athlete relationships. Due to the absence of a sportspecific framework for the study of dyadic coping, we used a total grounded theory methodology (Weed, 2009) to understand the dyadic coping processes between coaches and athletes working in individual sports.

\section{Method}

\section{Methodological Assumptions}

This study was informed by the first author's relativist ontology and transactional/subjectivist epistemological perspective. However, we acknowledge that throughout the study we encountered epistemological paradoxes and tensions that encouraged 
us as a research team to stretch and redefine the boundaries of our collective epistemologies (Wolgemuth et al., 2015). Thus, knowledge construction was not readily confined within the pluralist ideals of epistemology and ontology and, as a result, we considered constructionist grounded theory methods (see Charmaz, 2006) an appropriate guide to explore and understand the dynamic nature of interpersonal coping in coach-athlete relationships. Constructionist grounded theory encourages researchers to acknowledge the influence of their own experiences (e.g., career stages, and athletic background) on the research process and to seek to co-construct experience and meaning with research participants (Charmaz, 2006, 2014). Grounded theory methodology was considered an appropriate methodology for understanding dyadic coping because it provided a systematic yet flexible means to abstract understanding and insight relating to the dyadic coping phenomenon.

\section{Theoretical sampling \& data collection}

Consistent with grounded theory methodology (Charmaz, 2006; Weed, 2009), we used theoretical sampling to identify individuals who could aid the construction and development of tentative categories (Charmaz, 2014) relating to dyadic coping. We were sensitive to the notion that high-performance coaches and athletes operate in the "constraints of a dynamic, complex, and pressurized environment" (Thelwell, Wagstaff, Rayner et al., 2017, p. 44), spend a considerable amount of time together, and are exposed to shared environmental influences (Jowett \& Ntoumanis, 2004; Jowett \& Poczwardowski, 2007). Therefore, we perceived that these individuals were suitably placed to offer an initial insight into the manifestation and development of dyadic coping in coach-athlete relationships. Based on theoretical sampling procedures (Charmaz, 2006) and the aims of this study, we applied four phases of data collection and analysis.

Following institutional ethical approval, we began data collection by exploring current coaches' and athletes' experiences of the dynamic process of coping in the coach- 
athlete relationship (phase one). Initially, potential coaches and athletes were identified based on their level of expertise in coaching or their experience of competing at an Olympic or International level in an individual sport. We perceived that dyadic coping might be more salient for coaches and athletes who perform in individual sports because research has identified that these relationships are closer, more committed, and complementary (Rhind, Jowett, \& Yang, 2012). Coaches and athletes were contacted via email and invited to volunteer for this study. This initial correspondence informed each individual about the purpose of the study and the planned procedures and invited them to participate. The sample used in phase one consisted of six coaches $\left(M_{\mathrm{age}}=47.33, \mathrm{SD}=10.23\right.$ years $)$ and five athletes $\left(M_{\text {age }}=24.34, \mathrm{SD}=7.85\right.$ years $)$ who were coaching or competing at Olympic or International level $($ experience $=21.33, \mathrm{SD}=11.73$ years $)$, represented individual sports (i.e., ice dance, $\mathrm{n}=$ 2; tennis, $\mathrm{n}=2$; and track and field, $\mathrm{n}=7$ ), and who each volunteered to take part. Although attempts were made to recruit coach-athlete dyads, due to restrictions in availability the coaches and athletes who took part in this phase were unrelated. With this sample, we constructed tentative ideas about the process of dyadic coping in coach-athlete relationships.

Facilitated by memo writing and associated reflection, we chose to direct further sampling (phase two) toward athletes who had retired from high-performance sport. We believed that these individuals may be able to offer broadened perspectives on dyadic coping and may have enhanced abilities to reflect on their relevant experiences during sport (Stirling \& Kerr, 2009). Researchers have reported that memories and environments combine to offer the context of our current identity (Hoelscher \& Alderman, 2004). By exploring the experiences of retired Olympic athletes, we were able to capture an alternative perspective (Erickson, Backhouse, \& Carless, 2016) of dyadic coping in coach-athlete relationships. Using freely available information on websites and that gathered via chain referral, we approached 27 retired athletes via email and invited them to participate. From these 27 
individuals, two retired male athletes and one retired female athlete $\left(M_{\mathrm{age}}=43.27, \mathrm{SD}=\right.$ 11.98) volunteered to take part in the second phase of data collection. These individuals had experience of competing for Great Britain at an Olympic or Paralympic level $(M$ experience $=$ $17.67, \mathrm{SD}=9.09$ years $)$ in three different individual sports and, collectively, had competed at eight Olympic and Paralympic Games. The exploration of Olympic and Paralympic athletes enabled us to expand the range of variation within our sample and identify shared patterns that appear across cases, in turn supporting theoretical development (Palinkas et al., 2015). Due to the limited number of athletes in this phase of the study, we have refrained from specifying further demographic information to protect participants' anonymity and uphold our confidentiality agreement.

As the theory began to take shape during the first two phases of data collection, we identified the need to illuminate and clarify the relationships between our constructed categories (Charmaz, 2014; phase three). Thus, using our personal networks we approached coaches and athletes who we considered information rich, based on their experiences of coping with the demands of high-performance sport, and were able to provide an understanding of the dyadic coping processes that coaches and athletes experience (Bryant \& Charmaz, 2019). One coach (age $=54.58)$ and one athlete $($ age $=26.24)$ volunteered to take part in this third phase of data collection. These individuals were currently working in highperformance individual sports (i.e., track and field, triathlon).

Following phase three, we agreed that our sampling procedures and data collection had generated in-depth data, which showed patterns, categories, and variation in dyadic coping processes (Moser \& Korstjens, 2018). Thus, the fourth phase of the study aimed primarily to address the notion of theoretical saturation. Specifically, we aim to focus on the developing categories (Charmaz, 2011), establishing whether these categories are robust and appear well developed in terms of properties (Corbin \& Strauss, 2008; Charmaz, 2014; 
Holton, 2007). Here, we presented an initial substantive theory to coaches, athletes, and sport and exercise psychology practitioners (herein referred to as practitioners). The inclusion of practitioners in this phase of the study aimed to ensure that we were able to explore the experiences of those who were working closely with coaches and athletes, and to encourage knowledge exchange (Jones et al., 2017). We invited coaches, athletes, and practitioners to take part in the fourth phase of data collection by displaying posters around a university campus that informed individuals about the purpose of the study, the planned procedures, and invited them to participate. We did not specifically seek high-performance stakeholders instead, individuals across all levels of sport were invited to take part. This approach was used to more appropriately reflect the factors that influence dyadic coping in the coachathlete relationship, to help practitioners when designing appropriate and effective stress management interventions. Six coaches $(M$ age $=27.08, \mathrm{SD}=5.29)$, six athletes $\left(M_{\mathrm{age}}=22.57\right.$, $\mathrm{SD}=3.04)$, and five practitioners $(M \mathrm{age}=33.85, \mathrm{SD}=10.33)$ volunteered to take part in this phase of data collection.

\section{Data collection methods}

Two methods of data collection were used: interviews for phases one, two, and three and a workshop for phase four.

Interviews. All interviews were conducted face-to-face and recorded using a digital voice recorder (Olympus VN-733PC) to facilitate transcription and analysis. At the start of every interview, the interviewees completed, signed, and returned a written informed consent form. Each interviewee recorded demographic details, including the sport that they were involved with, their highest performance level, the number of years that they had been involved in their sport, and the length of their longest coach-athlete relationship. The interviews conducted during phase one were used to explore the concept of dyadic coping. During data collection, we were able to refocus our lines of questioning in accordance with 
the interviewees' experiences, which helped to refine our tentative categories. We organized and conducted the interviews $(M$ length $=62.69$ minutes, $\mathrm{SD}=6.65)$ to allow each interviewee to discuss their experiences of coping in coach-athlete relationships, reflect on their coping experiences throughout their sport careers, and discuss the developing substantive theory. Once each interview had been conducted and transcribed verbatim, each interviewee was sent a copy of their transcript and given an opportunity to comment on it and or share any further experiences they may have remembered. This approach was not used to establish a universal truth but, rather, to provide a practical opportunity to generate additional data and insight to dyadic coping in coach-athlete relationships (Smith \& McGannon, 2018).

Interview guides. Two independent but related semi-structured interview guides were developed to facilitate the interviews for phases one, two, and three. The processes of data collection and analysis in grounded theory are described as intertwined and recursive (Strauss \& Corbin, 1998). Thus, our interview guides were flexible to ensure that the interviews could move in unexpected directions and that later questions could be driven by emerging concepts and categories (Strauss \& Corbin, 1998). Previous dyadic coping literature (e.g., Bodenmann, 1995; Nicholls \& Perry, 2016; Staff et al., 2017a) provided a loose framework for the first interview guide, which was used to facilitate the interviews in phases one and two. The second interview guide, which facilitated the interviews in phase three, was developed from the constructed categories that were identified during the analysis of data in phases one and two. Each of the 16 interviews involved a combination of open questions and probes. For example, earlier interviews in phases one and two included questions such as "what demands do/did you face throughout the competitive season?" and probes that encouraged elaboration (e.g., "tell me more about that"). The second interview guide focused on establishing relationships between the constructed categories and, thus, specific questions were asked, including "how does your relationship with your coach influence dyadic coping?" and "how 
did your coach respond to the stressor you communicated?"

Workshop. At the start of the workshop, each participant completed, signed, and returned a written informed consent form and a demographics form. At this stage, each participant was informed that we would not be recording the workshop but that we would take notes on what was said throughout the session. We explained that our notes were necessary to capture what we were observing in the workshop, and that they would be used to challenge or corroborate our developing theory (Popper, 1959). The workshop (length $=90$ mins) was organized and conducted to offer each of the individuals an opportunity to share their experiences of dyadic coping in coach-athlete relationships in relation to the constructed theory. The length of the workshop was designed in line with Su and Reeve's (2011) recommendation that workshops between one and three hours in length are effective for knowledge development.

Workshop material. A Microsoft ${ }^{\circledR}$ PowerPoint ${ }^{\circledR}$ presentation was developed to facilitate the workshop, which included four group-based activities that are identified in Table 1. Case studies (Stroot, 2017) and problem-based learning (Savery, 2015) were used to encourage participants to discuss their understanding and real-world experiences of dyadic coping in coach-athlete relationships. Activity one consisted of a 15-minute brainstorming task on the stressors coaches and athletes face in sport. Participants were asked to consider if any of the stressors they identified were shared across social relationships and whom they might go to for support. Activity two focused on coping strategies. This section was delivered using a problem-based learning format (Savery, 2015), during which participants were given 20-minutes to discuss in small groups how they would respond to certain scenarios (e.g., athlete injury). The researcher facilitated these discussions and afterwards invited participants to share their thoughts with the wider group (Savery, 2015). During activity three, participants were introduced to the concept of dyadic coping. Case studies were used to aid 
understanding (Stroot, 2017). To conclude the workshop, participants were presented with our substantive theory of dyadic coping in coach-athlete relationships and asked to discuss the theory and their experiences of dyadic coping in relation to it. This discussion lasted approximately 30-minutes. Throughout the workshop, flipchart paper and pens were provided for groups to record elements of their discussion. These records were used later by the research team for scrutiny and reference.

[Table 1 here]

\section{Data analysis}

In line with constructionist grounded theory methodology (Charmaz, 2006), the interview data, workshop delivers notes, and any information collated on flipchart paper throughout the workshop were abductively analyzed using initial coding, focus coding, and theoretical categorization. Initial coding consisted of naming each segment of data and remaining open to all possible theoretical directions (Charmaz, 2006). This type of coding was provisional (e.g., open to other analytical constructions), comparative (e.g., compared across cases), and grounded in the data (Charmaz, 2014). To elaborate, "they had disordered eating, and it was affecting their life, their performance wasn't good, and they were always tired at training, so I had to sort it out" (Adam, coach), was initially coded as the "coaches perceived impact of the stressor on performance and training". Focus coding was used to synthesize the initial codes and advance the theoretical direction of the study. Here, we made informed decisions and comparisons across the initial codes (i.e., "coaches perceived impact of the stressor on performance and training" was synthesized into a focus code named "evaluations of stressor") and explored the emerging concepts in considerable depth during face-to-face discussions. We identified gaps in the data and, as such, were able to refine the questions asked in the subsequent interviews (e.g., When your partner communicates a stressor to you, how does this make you feel?). During later interviews, specific focus codes 
were elevated to theoretical categories (Charmaz, 2014) because we recognized the importance of these codes in understanding the manifestation and development of dyadic coping in coach-athlete relationships. To elaborate, "evaluations of the stressor" became a theoretical category named "evaluating the process" which represented the initial evaluation following the communication of the stressor, and subsequent evaluations around the availability of resources to cope with the stressor. We then explored the relationships between the categories. It is important to note that each stage of data analysis involved iterative processes (i.e., theoretical sampling, data collection, data analysis, and engaging with literature) that allowed a theoretical conceptualization of dyadic coping in coach-athlete relationships to be co-constructed by the research team and the interviewees (Charmaz, 2006, 2014). This recursive approach was applied within and between the individual interviews and workshop notes and, therefore, the categories and focus codes that we constructed in earlier iterations was reviewed and amended following subsequent data analysis (e.g., "evaluation the process" later became "appraising”; Lazarus, 1999; Lazarus \& Folkman, 1984).

The data analysis procedures were repeated as early as possible after each interview and the workshop until no new or relevant data was co-constructed regarding the categories, the categories appeared to be well developed, and the relationships between the categories were well established. During discussions and data analysis of the workshop data (i.e., delivers notes and information collated on flipchart paper), we identified that the majority of individuals who took part suggested that they understood and agreed with our theoretical conceptualization. However, during activity four, three coaches and one athlete raised questions relating to certain elements of our theory. In response, a critical dialogue was held among the group, which allowed individuals to voice their interpretations of the theory and to reflect on the constructed categories (Smith \& McGannon, 2018). A consensus was reached that the constructed categories effectively represented the differing experiences of the 
individuals who took part in the workshop. We affirmed that theoretical saturation had been achieved at this point because each of the categories was well developed and appropriate relationships were apparent between them (Charmaz, 2014). Practitioners commented on the practical application of the diagram. Individuals were asked to provide recommendations for the diagrammatic representation, which were highlighted and then subsequently discussed, based on the individuals' experiences. Appropriate changes were made to enable researchers and practitioners to work towards developing dyadic coping interventions that are relevant, accessible, and useful (Jones et al., 2017).

\section{Methodological rigor}

The reader is encouraged to judge this study using the following criteria set out by Charmaz (2006): (a) credibility, (b) originality, (c) resonance, and (d) usefulness. We sought to enhance the credibility of the findings by distributing and exploring the constructed theoretical conceptualization with multiple stakeholders (e.g., coaches, athletes, practitioners). These individuals acted as critical friends by providing a theoretical sounding board and, in doing so, promoted reflexivity by challenging our construction of knowledge (Smith \& McGannon, 2018). With reference to originality, the theoretical conceptualization presented in this study substantially extends the sport coping literature and encourages those working in sport to view coping through a social lens. Moreover, the findings of this study extend and support general psychology literature on dyadic coping in close personal relationships (e.g., Bodenmann, 1995; Rottman et al., 2015). A degree of resonance was achieved since those not directly involved in the immediate confines of theory building (i.e., attendees at the workshop) suggested that the theory represented their experiences of dyadic coping. We consider the constructed theory useful because naturalistic generalizability (Tracy, 2010) is present given that our findings can be "extrapolated beyond the immediate confines of the site, both theoretically and practically" (Charmaz, 2005, p. 528). 


\section{Results}

Using grounded theory methodology, we constructed a substantive theory, which captures the manifestation and development of dyadic coping in coach-athlete relationships (see Figure 1). The theoretical claims made in this paper are based on our experiences and the experiences of 13 coaches, 15 athletes, and five practitioners. The theory presents one core category (dyadic coping) and five supporting categories (moderators of dyadic coping, appraising, communication of the stressor, alternative levels of support, and outcomes of dyadic coping). The remainder of this results section describes each category of the substantive theory using words from the participants themselves. Inclusion of the participants' voices in this way helps to illustrate our interpretations of the participants' relevant experiences. Pseudonyms have been used throughout the results section to protect the identity of those who shared their experiences.

[Figure 1 here]

\section{Overview of the theory}

The substantive theory focuses on the interpersonal efforts of coaches and athletes to manage stressors. Our substantive theory postulates that dyadic coping begins when athletes and coaches communicate a stressor to their partner. From here, their partner will appraise the communicated stressor and the coping options that they have available. If an individual appraises the stressor that their partner has communicated as meaningful to their personal and relationship goals (i.e., harm/loss- stress goals, values, or beliefs that has already occurred; threat- future damage; challenge- anticipated gain, or benefit- gain that has already occurred; Lazarus, 1999) they will employ dyadic coping strategies to protect themselves and their social relationship. Alternatively, if an individual does not consider the stressor as meaningful or significant, they will provide alternative levels of support to their partner (i.e., social support or no support). If dyadic coping occurs, individuals will appraise the dyadic coping 
strategies used, which will shape the perceived outcomes for the individuals and their dyad, and their future coping efforts. Despite the linear process insinuated thus far, our theory suggests that the manifestation and development of dyadic coping is moderated by personal (e.g., athlete's age), relationship (e.g., trust), and organizational (e.g., relationship roles) characteristics and is, therefore, recursive in nature (Lazarus, 1993).

\section{Core category: Dyadic coping}

During the interviews, it became clear that coaches and athletes often shared their perceived stressor(s) with the other member of their dyad. As one athlete explained: "It wasn't hidden that he [coach] had cancer, it was very much there in both of us" (Robert, retired athlete). It was also evident that dyadic coping helped to manage shared stressors that were experienced in the coach-athlete relationship as illustrated in the following quote:

I had knee surgery and yeah, it's something you've got to get over together because it affects you both. Obviously, I can't train and obviously, he can't coach me. So, we had to work closely together and get a plan in place. (Tom, athlete)

The interviews revealed that dyadic coping strategies were employed by coaches and athletes to manage stressors. Coaches and athletes reported coping strategies, which were supported by workshop participants, and involved planning (e.g., discussing and confirming race tactics, routines), information seeking (e.g., visiting doctors together, gathering information online), perspective taking (e.g., reframing the situation, reflections on career), distraction and avoidance (e.g., humor, removing the dyad from the situation), emotional presence (e.g., enhancing self-belief, motivation, helplessness), and practical assistance (e.g., providing tangible resources, covering coaching sessions). For example, one coach spoke about a time he used perspective taking to enable himself and his athlete to manage a stressor:

He was having family issues, and it was affecting his performance. So we sat down and categorized what was most important to him. Although he put [the sport] first, it 
wasn't. It was third. In his behavior, in his attitude, and how things happened, he thought [the sport] was first but when we broke it down it was actually third, and he began to see it would only be first when other things were taken care of. (Chris, coach)

When referring to emotional presence, one athlete discussed how both she and her coach felt helpless following an unexpected mark at a competition, which allowed them to cope with the situation:

At [competition], for some reason, they gave me a major marking down on one of my [events], and that put me straight into like $4^{\text {th }}$ place. It was a massive shock, and I think we kind of just looked at each other and thought, "what do we do?" We couldn't do anything. We were powerless! We just said it was unfair of the judges to do that, which was kind of our way of coping with it. (Jane, athlete)

Interviewees revealed that coaches and athletes used dyadic coping to either: (a) support their partner or (b) manage the influence of their partner's stressor on themselves. The following quote is from a coach who used dyadic coping as a form of altruism because she appraised the stressor communicated as meaningful, showing concern for her athlete's well-being, and the impact the stressor would have on their training session:

I can remember one training time when we turned up and did the warm-up, and I knew things weren't right then. He was in tears, it [the stressor] had such a negative effect on him, and we sat for maybe two and a half hours. As a human, you can't help but feel something. He just talked and talked, and he just opened up and let everything out ... there was no point in training...he couldn't cope. I needed to help him. (Lucy, coach)

Interview data also revealed that although dyadic coping could be seen as selfless behavior, coaches and athletes also used dyadic coping as a self-serving behavior. For 
example, Lucy discussed how she supported her athlete to manage stressors as they impacted her:

The stressors that he [athlete] brings to practice affect what we are trying to achieve in that session. For me, that's what I find stressful because I know I'm going to have to change the session and help him work things out, otherwise it is a waste of a two-hour session for both of us. (Lucy, coach)

\section{Supporting category: Communication of the stressor}

Coaches and athletes reported using both verbal and non-verbal communication to share a stressor and promote dyadic coping. The interviewees and workshop participants suggested that they would verbally communicate the stressor to their partners:

Things were getting a bit on top of me and because of that I wasn't [training] particularly great. So, I told him that the past few weeks I hadn't been feeling that great, and actually I fainted at one lecture just because it got a bit much. (Jane, athlete)

Coaches and athletes may also communicate a stressor to their partner non-verbally via their behaviors and body language. During the interviews, it became clear that coaches and athletes could identify "trigger points" (Lucy, coach) when their partner was unable to cope with a stressor. For example, participants frequently reported noticing if their partner "turned up grumpy" (Jane, athlete) or "looked nervous" (Maria, coach). The following quote from a coach emphasizes this point: "you can normally tell if something is up by the way they hit the ball or how they are responding to you" (Lucy, coach). Within the workshop, it was noted that "three of the sport and exercise psychologists discussed the non-verbal communication of stressors, and noted that coaches were expert 'noticers' of changes in athlete behavior" (Workshop deliverer).

\section{Supporting category: Appraising}


Within the substantive theory, we suggested that dyadic coping was influenced by coaches' and athletes' conscious and or unconscious evaluations of stressors (Lazarus, 1999). Coaches and athletes discussed (a) appraising the meaning and significance of the stressor for their individual (e.g., athlete appraises coach's stressor as threatening their performance goals) and relationship goals (e.g., coach appraises athlete's stressor as an opportunity to develop openness and trust in coach-athlete relationship), (b) appraising the coping strategies that they had available, and (c) appraising the dyadic coping strategies that they used.

\section{Appraising the meaning and significance of the stressor for individual and}

relationship goals. Interviews conducted during the later phases of data collection revealed that, following the communication of a stressor, coaches and athletes would appraise the stressor in relation to their individual goals. Reflecting on her past experiences, Hannah recalled:

The coaches were running around like headless chickens. They were nervous, and you can't help thinking, well they've been with me for the last four years of my life...are they nervous because they think I'm not capable of winning? (Hannah, retired athlete) In addition to appraisals relating to individual goals, coaches and athletes often appraised the stressor communicated by their partner in relation to their relationship goals: "Anything that might influence performance, as a coach I want to know because it can impact our target. Once you know [about the stressor] you try and advise, control, and cope with all of those things" (Adam, coach). Despite coaches' and athletes' observations that communicating a stressor can "transfer a bit of the stress" (John, coach) to the partner, participants recalled times when they had appraised a communicated stressor as not significant or meaningful to their individual or relationship goals. One athlete explained: "I try not to let [the stressor] affect me. I just have to think about myself, and I need to focus on what I'm doing" (Jenna, athlete). 
Appraising the coping strategies available. The athletes and coaches perceived their partner's support as a means to cope with shared stressors: "When it's getting difficult, I know he is there and will have input" (Paul, athlete). In line with previous literature, we interpreted this appraising of available coping as a form of secondary appraising (see Lazarus, 1999; Lazarus \& Folkman, 1984). The interviewees and workshop participants believed that the presence of a partner can supplemented and extended available coping strategies. One coach explained: "I think being friends and being able to talk to each other and share things meant we could cope with it [the stressor] together" (Chris, coach).

Appraising the dyadic coping strategies used. Throughout the study, it became clear that following the use of dyadic coping, both members of the dyad often appraised the dyadic coping strategies that they had used. Athletes reported that, at times, dyadic coping "helped [them] realize that it wasn't as bad as [they] first interpreted" (Jenna, athlete) but that it could "also [make] it more stressful" (Jane, athlete). The following quote is from a coach who appraised the use of dyadic coping strategies following the communication of a stressor from their athlete: "You can see they are frustrated, so you try to keep yourself calm [to support them], but if you're too calm then they can think you're not interested or not taking them seriously" (John, coach).

\section{Supporting category: Alternative levels of support}

During the interviews with retired athletes, we began to recognize that when coaches and athletes appraised the stressor communicated by their partner as not meaningful to their personal or relationship goals support was absent or they provided unidirectional support (i.e., social support) to their partner. As one athlete explained:

When you're under pressure you don't want any more [pressure] getting in there or added on top, so, I hope there is another form of support for a coach, outside of that dynamic [the coach-athlete relationship], that they might be able to go off and vent to. 
(Hannah, retired athlete)

Furthermore, we noted that an individual's appraisal of the stressor could shape the provision of support in the coach-athlete dyad. Karl, a retired athlete, reflected on his past experiences:

Bill just wanted people to perform at all the different levels, and he didn't get involved in all the intimate stories. He was not the coach that picked you up at home, drove you to the venue, that's not him, he's a trainer. He wasn't intimately involved with anyone, so if you got injured, he just moved on, he just didn't show that sort of interest.

Following these observations, we returned to the data collected during phase one and identified that interviewees had also discussed times when they had not appraised the stressor as meaningful and, thus, made no clear attempt to engage in supporting their partner when managing stressors (i.e., no support). One coach explained, "I'm the outside observer, I'm not in the emotional bubble goldfish bowl" (Simon, coach). Interestingly, Simon also suggested that, following the communication of a stressor from his athletes, at times he provided unidirectional support (i.e., social support; see Tamminen \& Holt, 2012) to his athletes, in an attempt to support their well-being (e.g., pleasure attainment and pain avoidance, Nicholls, Levy, Carson, Thompson, \& Perry, 2016):

One girl's mum and dad were divorcing, so you listen, but you're not upset because as a coach you've got to separate from that. So sometimes you say, "that's enough now, that's enough now Charlotte, we've done an hour, you've done high-quality work go and spoil yourself." (Simon, coach)

\section{Supporting category: Outcomes of dyadic coping}

Interviewees and workshop participants discussed several outcomes of dyadic coping in coach-athlete relationships. Specifically, coaches and athletes highlighted that dyadic 
coping had implications for performance, relationship satisfaction, and psychological wellbeing. One athlete explained how she perceived that her coach's dyadic coping influenced her pleasure attainment and pain avoidance (Nicholls et al., 2016) and, thus, supported her performance:

I was behind by such a large deficit but he just appeared so calm. He said, “don’t worry, just leave it to me, I'm working on it. There is going to be a big tornado, and it will be ok." He really calmed me down, and I won. (Hannah, retired athlete) Interviewees described how dyadic coping helped them to "learn how to overcome difficulties" (Jane, athlete) because it made them "resourceful and opened [their] eyes to what [they] were capable of' (Robert, retired athlete). Coaches and athletes identified that dyadic coping positively influence their psychological well-being. One coach identified that their experiences of dyadic coping led to personal growth: "the more mad stuff [stressors] that happens to us, we learn how to cope, and if we do it [cope] badly the first time, we won't try to do the same next time" (Chris, coach).

Despite this, it was clear that athletes, coaches, and practitioners agreed that dyadic coping could have both "positive and negative" (Jane, athlete) outcomes. For example, one athlete discussed how his performance decreased as a result of employing dyadic coping strategies to support his coach: "I didn't handle [the added pressure] particularly well, and my performance tracked his illness. Unfortunately, I couldn't help him. As he got ill I got slower" (Robert, retired athlete). Importantly, participants identified "when coaches share too many stressors, this can impact an athlete's self-esteem and make it really hard" (Participants workshop notes), thus, dyadic coping can negatively influence an athlete's psychological well-being. Interviewees and workshop participants recognized that dyadic coping could potentially increase an athlete's dependency on the coach-athlete relationship and, thus, hinder an athlete's development. Information collated from the workshop read, "-The athlete 
is too dependent on the coach. -Loss of ownership of the stressor. -Will athlete know how to cope in other situations?

\section{Supporting category: Moderators of dyadic coping}

Interviews and conversations with workshop participants revealed that organizational, personal, and relationship characteristics moderated the manifestation and development of dyadic coping.

Organizational characteristics. Coaches and athletes reported that the organization in which an individual is operating had an influence on the manifestation of dyadic coping in coach-athlete relationships. Interviewees and workshop participants revealed that roles in the coach-athlete relationship (e.g., support giver and receiver) and professionalism (e.g., code of conduct) altered the way in which the coaches and athletes communicated stressors to their partner. To elaborate, it was often considered inappropriate for a coach to communicate a stressor to his or her athlete: "It's kind of similar to a parent unloading their stress on a child, you should try to avoid it and deal with it yourself" (Jenna, athlete). A coach echoed this:

Hierarchy is not the right word but it's kind of like parent-child, teacher-pupil, bossworker kind of thing, there is that level. You don't want to be seen as weak as you've got to be that rock, that one that's there. (Simon, coach)

Coaches, athletes, and practitioners felt that organizational characteristics (e.g., roles in the relationship) could also influence an individual's appraisals of a stressor communicated in the coach-athlete relationship, which is illustrated in the following quote from a retired athlete: "It's very one-sided. I'm sure there were stressors going on in his life but I don't think I was responsive [to them]. He was there to serve not to be served" (Karl, retired athlete).

In addition, coaches and athletes felt that the coaching environment moderated the level of support (i.e., dyadic coping, no support, or social support) that they provided to or 
received from their partner. One athlete felt that "the amount of autonomy the coaches have [over an athlete's training] makes the difference and that is shaped by the environment" (Robert, retired athlete). A workshop participant noted that "if the coach has other athletes whom they are working with at the same time" (e.g., one to one or group-based training) this could influence the dyadic coping process. This supports the following quote: "Time is of the essence. They need to be training while they are there. So anytime I take out to deal with an individual's difficulties might detract from the attention I give to everyone else" (John, coach).

Personal characteristics. Interviewees and workshop participants identified that personal characteristics such as age, personality, the effectiveness of individual coping, and previous coping efforts moderated dyadic coping processes. Lucy (coach) suggested that the communication of a stressor could be moderated by an athlete's age: "With James I would probably say I've had a stressful day because it's kind of working with an adult" (Lucy, coach). The interviewees and workshop attendees suggested that the use of dyadic coping was "down to personalities and the way people operate" (Simon, coach). Although dyadic coping provided a means to manage stressors, some coaches and athletes suggested that “...you [sometimes] don’t want to talk about your problems because there is a kind of stigma around stuff like that" (Tom, athlete) and, thus, it was useful to "learn to do stuff [cope] by yourself" (Tom, athlete). Coaches and practitioners suggested that athletes' experiences of coping with stressors throughout their career developed their individual coping strategies and, as such, may influence dyadic coping in coach-athlete relationships. Michael (coach) illustrates this point in the following quote: "What an athlete finds stressful in the early stages of their development they eventually learn to cope with [themselves].”

Relationship characteristics. Coaches, athletes, and practitioners suggested that relationship length, relationship quality, togetherness, and relationship trust influenced dyadic 
coping in coach-athlete relationships. Recalling his past experiences, Simon (coach) explained:

You spend so many hours [together], and you travel all over the world so, you know, the emotional relationship, and the things which affect you [stressors] can actually become very immersive in that sense ... you are in a tight relationship, you've got shared goals, shared outcomes. If something affects one of you, it affects both of you. One athlete discussed how his positive relationship with his coach promoted communication of the stressor and, thus, dyadic coping: "He is not just my coach, he is like a friend, like a father, I just tell him everything, and it makes me feel better. I don't have to stress about anything we just manage it between us" (Alex, athlete). Furthermore, one athlete explained how the bond that her and her coach had developed over the length of their relationship prompted dyadic coping efforts:

When I didn't make the [championship team], I could see that she felt it with me, but we got through it together. I guess it's the kind of bond you get through the years, back in the day I would've just gone home and cried. (Jenna, athlete)

Coaches and athletes also believed that relationship trust was a precursor to dyadic coping, "it comes back to trust and if you are open and you're honest and transparent about things then you can deal with it" (Adam, coach).

\section{Discussion}

To our knowledge, this is the first study to use constructionist grounded theory methodology as a guide to present a theoretical explanation of dyadic coping in coach-athlete relationships. Further, it is the first published attempt to theoretically explain and understand dyadic coping between sports coaches and athletes. The substantive theory presented in this study is a construction of the interaction between the research team and the people who shared their stories (Guba \& Lincoln, 1994). Therefore, this study is neither a complete or 
exhaustive exploration of this topic but captures one interpretation of the dyadic coping process for coaches and athletes in individual sports. With this in mind, we encourage the reader to interpret the findings in ways that are meaningful to them and to explore alternative interpretations to those that are presented here (Smith, 2018). The theory presented does, however, provide naturalistic generalizability (Tracey, 2010) as the theory contributes to the limited evidence on dyadic coping in performance-based dyads (Staff et al., 2017b), and its concepts support and extend current interpersonal coping research and theories (Bodenmann, 1995; Lyons et al., 1998).

In sport psychology, a focus on the intrapersonal nature of coping has dominated coping research and scholars have predominately focused on how athletes cope with the demands of high-performance sport (Crocker, Tamminen, \& Gaudreau, 2015; Nicholls, Taylor et al., 2016). Using the transactional perspective (Lazarus \& Folkman, 1984), our research extends this knowledge base by addressing the interactive elements of coping when coaches and athletes communicate, appraise, and cope with a stressor together. Our findings suggest that coaches and athletes communicate a stressor using both verbal and non-verbal communication. This supports the work of other sport psychology scholars who have reported that athletes can identify when their coaches are experiencing stress by observing changes in their coaches' behavior (Thelwell, Wagstaff, Chapman, \& Kenttä, 2017; Thelwell, Wagstaff, Rayner et al., 2017). Our findings showed that when coaches and athletes individually appraised a stressor communicated by their partner as meaningful, they used dyadic coping to either support their partner or to manage the influence of their partner's stressor on themselves. Interestingly, some of the athletes interviewed discussed how they supported their coaches during stressful periods. These findings extend the literature because it is generally accepted that coaches aim to provide a nurturing environment to facilitate athletes' growth (Tamminen \& Gaudreau, 2014). Contrary to these suggestions, our study 
acknowledges the role that an athlete plays in supporting his or her coach and, supports previous research that identified the impact of an athletes' use of dyadic coping strategies on coaches' perceptions of relationship quality (Nicholls \& Perry, 2016). Neely et al. (2017) reported that parent-athlete dyads appraised stressors as shared and highlighted that interpersonal relationships played an important role in an athlete's ability to cope with the demands of elite sport. By identifying the dyadic coping process in coach-athlete relationships, our findings provide novel insight to how coaches and athletes cope with the demands of high-performance sport, which extends understanding of the influence of social relationships on coping.

Our findings support and extend previous interpersonal coping research and theories (e.g., STM and CCM) by proposing a theory that is applicable to coach-athlete relationships and, thus, respond to calls for research on dyadic coping in performance-based dyads (Didymus, 2017; Staff et al., 2017b; Tamminen \& Gaudreau, 2014). By exploring the experiences of coaches, athletes, and practitioners working across individual sports, we were able to identify that communication of the stressor, appraising, and moderators of dyadic coping (i.e., organizational, personal, and relationship characteristics) promoted dyadic coping actions, which encouraged further appraising and personal and social outcomes for both members of the dyad. Previous interpersonal coping theorists (Bodenmann, 1995; Lyons et al., 1998) have identified the importance of communication of the stressor within the interpersonal coping process. Indeed, the communication of a stressor within close personal relationships has been shown to influence interpersonal coping strategies and to promote positive affect (see Staff et al., 2017b). Our substantive theory extends understanding of dyadic coping by exploring the phenomenon using the experiences of coaches, athletes, and practitioners. It also recognizes the continuous role of appraising throughout the dyadic coping process, and the negative implications dyadic coping may have for performance, 
relationship satisfaction, and psychological well-being.

The transactional approach to stress (Lazarus \& Folkman, 1984; Lazarus, 1999) that is predominantly adopted in research that explores coping in sport (e.g., Burlot et al., 2016; Didymus, 2017), proposed that an individual's coping actions are influenced by their appraisals, which in turn change the person-environment transaction (Crocker et al., 2016). While the transactional approach has informed the theory presented in this paper, the process of appraising during dyadic coping experiences was found to influence not only dyadic coping actions but also an individual's personal and social outcomes. Lyons et al. (2016) identified the role of appraisal in interpersonal coping and conceptualized dyadic appraisal as the way in which individuals in close personal relationships acknowledge shared stressors (i.e., ours or mine approach). Nevertheless, to the best of our knowledge, no literature has identified the role of appraising in shaping an individual's perceived outcomes of dyadic coping. Scholars have explored the notion of coping effectiveness and define this as "the ability of people to manage demands that tax or exceeds a person's resources" (Lazarus \& Lazarus, 2006, p.205). However, our research offers evidence to support that the effectiveness of dyadic coping is not simply an outcome modality following the employment of coping strategies as suggested in previous coping research (e.g., Nicholls \& Polman, 2007) but a cognitive evaluation that shapes the relationship between stress and its social and psychological outcomes. One explanation for this discrepancy may be the social interactions inherent in dyadic coping processes. These interactions may encourage appraisals of the coping strategies used, which has implications for performance, relationship satisfaction, and psychological well-being. These findings contribute to knowledge on coping as an interpersonal phenomenon and develop the intellectual agenda of stress literature in sport.

A noteworthy contribution of this study to the literature relates to the part of our theory that focuses on the negative outcomes of dyadic coping. The majority of interpersonal 
coping research has highlighted that dyadic coping strategies has adaptive outcomes for those in close personal relationships (Staff et al., 2017b). While the identification of positive outcomes following dyadic coping is valuable for academics and practitioners who seek to promote positive affect in close personal relationships, addressing the potentially negative outcomes is also important because it shows that dyadic coping can be both adaptive and maladaptive. We propose that dyadic coping may encourage negative performance outcomes, poor relationship functioning, and diminished psychological well-being if one partner appraises the coping strategies used as ineffective. While no other published research has provided a theoretical overview of the potentially negative consequences of dyadic coping, our findings do support research in general psychology (e.g., Donato et al., 2012; Rottman et al., 2015), which suggests that dyadic coping strategies can reduce relationship functioning and personal health. In sport, these salient and original findings show that supportive coaching behaviors (e.g., closeness, commitment; Jowett, 2007) could, in some circumstances, be detrimental for an athlete's development. Indeed, Nicholls, Levy et al. (2016) suggested that highly committed coach-athlete relationships could encourage negative consequences (i.e., threat appraisals). Our evidence relating to the negative outcomes of dyadic coping that arise from close coach-athlete relationships offers an important message to those working in sport. Specifically, dyadic coping has the potential to have negative implications for athlete and coach psychological well-being, relationship functioning, and performance. Therefore, it is vital that practitioners, researchers, and organizations acknowledge these issues when developing interventions for coaches and athletes.

The proposed theory should be considered in light of the strengths and limitations of this study. One such strength relates to the coaches, athletes, and practitioners who volunteered. Specifically, the use of both current and retired athletes provided various narratives and new insight during the construction of the substantive theory. In addition, the 
use of grounded theory methods ensured we remained focused on the experiences of the interviewees and on enhancing the credibility of our findings. Equally, the presentation of quotes to support the theory allowed the reader to stay close to the data, make choices based on their own understanding (i.e., naturalistic generalizations; Tracey, 2010), and to acknowledge the perspectives of the coaches and the athletes through the individuals' voices (Schinke et al., 2016). Despite the strengths of this study, the substantive theory presented does not consider the role of individual coping, specifically how elements of our theory (e.g., stress communication) may influence individual coping strategies. Future research should pay closer attention to understanding the full stress and coping process in coach-athlete dyads to furnish practitioners and organizations with fruitful intervention ideas. Furthermore, our theory fails to recognize the wider social structures of sport (e.g., parent-athlete dyads, coachparent dyads). That said, the approach we took allowed us to present a focused version of dyadic coping on coach-athlete relationships, which future research can build on. It should also be noted that, when interviewing participants, we captured a snapshot of dyadic coping in their coach-athlete relationships because theoretical sampling and the developing theory guided us (Wimpenny \& Gass, 2000). While our findings contribute to knowledge development, interviewing coach-athlete dyads using longitudinal methods would have allowed us to observe changes across time and explore the individual and related experiences of those working in a range of contexts.

To conclude, this study has developed a new substantive theory, which acknowledges that the coach-athlete relationship may foster interpersonal coping resources that can have long-term effects on coaches' and athletes' well-being and functioning. This study provides encouraging support for other interpersonal coping theories (e.g., Bodenmann, 1995; Lyons et al., 1998), which suggest that the close personal relationships (e.g., romantic relationships) people develop throughout life may form the vehicle through which interpersonal coping can 
occur. However, our theory moves beyond a universal view of dyadic coping by illustrating the processes that influence dyadic coping in coach-athlete relationships. This is important because our findings show that dyadic coping has implications for athlete and coach psychological well-being, relationship functioning, and performance. We envisage that our theory will encourage a wider program of research that will better place academics and practitioners to support coaches and athletes when managing stress in high-performance sport. 


\section{References}

Ainsworth, M. D. S., Blehar, M. C., Waters, E., \& Wall, S. (1978). Patterns of attachment: A psychological study of the Strange Situation. Hillsdale, NJ: Erlbaum.

Bergstraesser, E., Inglin, S., Hornung, R., \& Landolt, M. A. (2015). Dyadic coping of parents after the death of a child. Death Studies, 39, 128-138.

doi:10.1080/07481187.2014.920434

Bryant, A., \& Charmaz, K. (2019). The SAGE handbook of current developments in grounded theory. London, United Kingdom: SAGE Publications Limited.

Bodenmann, G. (1995). A systemic-transactional conceptualization of stress and coping in couples. Swiss Journal of Psychology, 54, 34-49. Retrieved from www.hogrefe.ch/index.php/sw iss-journal-of-psychology.html/

Bodenmann, G. (1997). Dyadic coping: A systemic-transactional view of stress and coping among couples: Theory and empirical findings. European Review of Applied Psychology, 47, 137-141. Retrieved from www.journals.elsevier.com/revueeuropeenne-de-psychologie-appliquee-european-review-of-applied-psychology

Burlot, F., Richard, R., \& Joncheray, H. (2016). The life of high-level athletes: The challenge of high performance against the time constraint. International Review for the Sociology of Sport, 1-16. doi:10.1177/1012690216647196

Charmaz, K. (2005). Grounded theory: Methods for the 21st century. Handbook of Qualitative Research. London, United Kingdom: Sage Publications Ltd.

Charmaz, K. (2006). Constructing grounded theory: A practical guide through qualitative research. London, United Kingdom: Sage Publications Ltd.

Charmaz, K. (2011). Grounded theory methods in social justice research. In N.K. Denzin \& Y. Lincoln (Eds.). Handbook of qualitative research (pp. 359-380). Thousand Oaks, CA: Sage. 
Charmaz, K. (2014). Constructing grounded theory. London, United Kingdom: Sage Publications Ltd.

Corbin, J., \& Strauss, A. (2008). Basics of qualitative research: Techniques and procedures for developing grounded theory. Los Angeles, LA: Sage.

Crocker, P.R.E., Tamminen, K. A., \& Gaudreau, P. (2015). Coping in sport. In S. Hanton \& S. Mellalieu (Eds.), Contemporary advances in sport psychology: A review (pp.2867). New York City, NY: Routledge.

Davis, L., Appleby, R., Davis, P., Wetherell, M., \& Gustafsson, H. (2018). The role of coachathlete relationship quality in team sport athletes' psychophysiological exhaustion: implications for physical and cognitive performance. Journal of Sports Sciences, 36, 1985-1992. doi:10.1080/02640414.2018.1429176

Didymus, F. F. (2017). Olympic and international level sports coaches' experiences of stressors, appraisals, and coping. Qualitative Research in Sport, Exercise \& Health, 9, 214-232. doi:10.1080/2159676X.2016.1261364

Donato, S., Iafrate, R., Bradbury, T. N., \& Scabini, E. (2012). Acquiring dyadic coping: Parents and partners as models. Personal Relationships, 19, 386-400. doi:10.1111/j.1475-6811.2011.01368

Erickson, K., Backhouse, S. H., \& Carless, D. (2016). “The ripples are big”: Storying the impact of doping in sport beyond the sanctioned athlete. Psychology of Sport and Exercise, 24, 92-99. doi:10.1016/j.psychsport.2016.01.010

Flick, U. (2018). Designing qualitative research. Thousand Oaks, CA: Sage Publications Ltd. Fraser-Thomas, J., \& Côté, J. (2009). Understanding adolescents' positive and negative developmental experiences in sport. The Sport Psychologist, 23, 3-23. doi:10.1123/tsp.23.1.3

Guba, E. G., \& Lincoln, Y. S. (1994). Competing paradigms in qualitative research. In N. K. 
Denzin \& Y. S. Lincoln (Eds.), Handbook of qualitative research (pp. 105-117). Thousand Oaks, CA: Sage Publications Ltd.

Hoelscher, S., \& Alderman, D. H. (2004). Memory and place: Geographies of a critical relationship. Social \& Cultural Geography, 5, 347-355. doi:10.1080/1464936042000252769

Holt, N. L., Knight, C., \& Tamminen, K. A. (2012). Grounded theory. In K. Armour \& D. MacDonald (Eds.), Research methods in physical education and youth sport (pp. 276294). Oxon, United Kingdom: Routledge.

Holton, J. A. (2007). The coding process and its challenges. In A. Bryant \& K Charmaz (Eds.), The sage handbook of grounded theory (pp. 265-289). London, United Kingdom: Sage.

Jones, B., Till, K., Emmonds, S., Hendricks, S., Mackreth, P., Darrall-Jones, J., ... \& Potts, N. (2017). Accessing off-field brains in sport; An applied research model to develop practice. British Medical Journal of Sports Medicine, Advanced online publication. doi:10.1136/bjsports-2016-097082

Jowett, S. (2007). Interdependence analysis and the $3+1 \mathrm{Cs}$ in the coach-athlete relationship. In S. Jowett \& D. Lavallee (Eds.), Social psychology in sport (pp. 15-27). Champaign, IL: Human Kinetics.

Jowett, S., \& Ntoumanis, N. (2004). The coach-athlete relationship questionnaire (CART-Q): Development and initial validation. Scandinavian Journal of Medicine \& Science in Sports, 14, 245-257. doi:10.1111/j.1600-0838.2003.00338.x

Jowett, S., \& Poczwardowski, A. (2007). Understanding the coach-athlete relationship. In S. Jowett \& D. Lavallee (Eds.), Social Psychology in Sport (pp. 3-14). Champaign, IL: Human Kinetics.

Kaye, M. P., Frith, A., \& Vosloo, J. (2015). Dyadic anxiety in youth sport: The relationship 
of achievement goals with anxiety in young athletes and their parents. Journal of Applied Sport Psychology, 27, 171-185. doi:10.1080/10413200.2014.970717

Kuo, B. C. (2012). Collectivism and coping: Current theories, evidence, and measurements of collective coping. International Journal of psychology, 48, 374-388. doi:10.1080/00207594.2011.640681

Lazarus, R. S. (1993). Coping theory and research: Past, present, and future. Psychosomatic Medicine, 55, 234-247. doi:10.1097/00006842-199305000-00002

Lazarus, R. S. (1999). Stress and emotion: A new synthesis. New York City, NY: Springer.

Lazarus, R. S., \& Folkman, S. (1984). Stress, appraisal, and coping. New York City, NY: Springer.

Lazarus, R. S., \& Launier, R. (1978). Stress-related transactions between person and environment. In L. A. Pervin \& M. Lewis (Eds.), Perspectives in interactional psychology (pp. 287-327). Boston, MA: Springer.

Lazarus, R. S., \& Lazarus, B. N. (2006). Coping with aging. New York City, NY: Oxford University Press.

Lyons, R. F., Mickelson, K. D., Sullivan, M. J., \& Coyne, J. C. (1998). Coping as a communal process. Journal of Social and Personal Relationships, 15, 579-605. doi:10.1177/0265407598155001

Lyons, K. S., Miller, L. M., \& McCarthy, M. J. (2016). The roles of dyadic appraisal and coping in couples with lung cancer. Journal of Family Nursing, 22, 493-514. doi:10.1177/1074840716675976

Moser, A., \& Korstjens, I. (2018). Series: Practical guidance to qualitative research. Part 3: Sampling, data collection and analysis. European Journal of General Practice, 24, 918. doi:10.1080/13814788.2017.1375091

Neely, K. C., McHugh, T. L. F., Dunn, J. G., \& Holt, N. L. (2017). Athletes and parents 
coping with deselection in competitive youth sport: A communal coping perspective. Psychology of Sport \& Exercise, 30, 1-9. doi:10.1016/j.psychsport.2017.01.004

Nicholls, A. R., Levy, A. R., Carson, F., Thompson, M. A., \& Perry, J. L. (2016). The applicability of self-regulation theories in sport: goal adjustment capacities, stress appraisals, coping, and well-being among athletes. Psychology of Sport and Exercise, 27, 47-55. doi:10.1016/j.psychsport.2016.07.011

Nicholls, A. R., Levy, A. R., Jones, L., Meir, R., Radcliffe, J. N., \& Perry, J. L. (2016). Committed relationships and enhanced threat levels: Perceptions of coach behavior, the coach-athlete relationship, stress appraisals, and coping among athletes. International Journal of Sports Science \& Coaching, 11, 16-26. doi:10.1177/1747954115624825

Nicholls, A. R., \& Perry, J. L. (2016). Perceptions of coach-athlete relationship are more important to coaches than athletes in predicting dyadic coping and stress appraisals: An actor-partner independence mediation model. Frontiers in Psychology, 7, 447. doi:10.3389/fpsyg.2016.00447

Nicholls, A. R., \& Polman, R. C. (2007). Coping in sport: A systematic review. Journal of Sports Sciences, 25, 11-31. doi:10.1080/02640410600630654

Nicholls, A. R., Taylor, N. J., Carroll, S., \& Perry, J. L. (2016). The development of a new sport-specific classification of coping and a meta-analysis of the relationship between different coping strategies and moderators on sporting outcomes. Frontiers in Psychology, 7, 1674. doi:10.3389/fpsyg.2016.01674

Palinkas, L. A., Horwitz, S. M., Green, C. A., Wisdom, J. P., Duan, N., \& Hoagwood, K. (2015). Purposeful sampling for qualitative data collection and analysis in mixed method implementation research. Administration and Policy in Mental Health and Mental Health Services Research, 42, 533-544. doi:10.1007/s10488-013-0528-y 
Popper, K. (1959). The logic of scientific discovery. London, United Kingdom: Hutchinson.

Rottmann, N., Hansen, D. G., Larsen, P. V., Nicolaisen, A., Flyger, H., Johansen, C., \& Hagedoorn, M. (2015). Dyadic coping within couples dealing with breast cancer: A longitudinal, population-based study. Health Psychology, 34, 486-495. doi:10.1037/hea0000218

Savery, J. (2015). Overview of problem-based learning: Definitions and distinctions. In A. Walker, H. Leary, C. E. Hmelo-Silver, \& P. A. Ertmer (Eds.), Essential readings in problem-based learning (pp. 5-15). West Lafayette, IN: Purdue University Press.

Schinke. R. J., Blodgett, A. T., McGannon, K. R., Ge, Y., Oghene, O., \& Seanor, M. (2016). Adjusting to the receiving country outside the sport environment: A composite vignette of Canadian immigrant amateur elite athlete acculturation. Journal of Applied Sport Psychology, 29, 270-284. doi:10.1080/10413200.2016.1243593

Smith, B. (2018). Generalizability in qualitative research: Misunderstandings, opportunities and recommendations for the sport and exercise sciences. Qualitative Research in Sport, Exercise and Health, 10, 137-149. doi:10.1080/2159676X.2017.1393221

Smith, B., \& McGannon, K. R. (2018). Developing rigor in qualitative research: Problems and opportunities within sport and exercise psychology. International Review of Sport and Exercise Psychology, 11, 101-121. doi:10.1080/1750984X.2017.1317357

Staff, H. R., Didymus, F. F., \& Backhouse, S. H. (2017a). Coping rarely takes place in a social vacuum: Exploring antecedents and outcomes of dyadic coping in coach-athlete relationships. Psychology of Sport \& Exercise, 30, 91-100. doi:10.1016/j.psychsport.2017.02.009

Staff, H.R., Didymus, F.F., \& Backhouse, S.H. (2017b). The antecedents and outcomes of dyadic coping in close personal relationships: A systematic review and narrative synthesis. Anxiety, Stress, \& Coping, 30, 498-520. 
doi:10.1080/10615806.2017.1329931

Stebbings, J., Taylor, I. M., \& Spray, C. M. (2016). Interpersonal mechanisms explaining the transfer of well-and ill-being in coach-athlete dyads. Journal of Sport \& Exercise Psychology, 38, 292-304. doi:10.1123/jsep.2015-0172

Stirling, A. E., \& Kerr, G. A. (2009). Abused athletes' perceptions of the coach-athlete relationship. Sport in Society, 12, 227-239. doi:10.1080/17430430802591019

Strauss, A., \& Corbin, J. (1998). Basics of qualitative research: Techniques and procedures for developing grounded theory. Thousand Oaks, CA: Sage Publications Ltd.

Stroot, S. A. (2017). Case studies in physical education: Real world preparation for teaching. New York City, NY: Routledge.

Su, Y. L., \& Reeve, J. (2011). A meta-analysis of the effectiveness of intervention programs designed to support autonomy. Educational Psychology Review, 23, 159-188. doi:10.1007/s10648-010-9142-7

Tamminen, K. A., \& Gaudreau, P. (2014). Coping, social support, and emotional regulation in teams. In M. R. Beauchamp \& M. A. Eys (Eds.), Group dynamics in exercise and sport psychology: Contemporary themes (pp. 222-239). New York City, NY: Routledge.

Tamminen, K. A., \& Holt, N. L. (2012). Adolescent athletes' learning about coping and the roles of parents and coaches. Psychology of Sport \& Exercise, 13, 69-79. doi:10.1016/j.psychsport.2011.07.006

Tamminen, K. A., Poucher, Z. A., \& Povilaitis, V. (2017). The car ride home: An interpretive examination of parent-athlete sport conversations. Sport, Exercise, and Performance Psychology, 6, 325-339. doi:10.1037/spy0000093

Thelwell, R. C., Wagstaff, C. R., Chapman, M. T., \& Kenttä, G. (2017). Examining coaches' perceptions of how their stress influences the coach-athlete relationship. Journal of 
Sports Sciences, 35, 1928-1939.

Thelwell, R. C., Wagstaff, C. R., Rayner, A., Chapman, M., \& Barker, J. (2017). Exploring athletes' perceptions of coach stress in elite sport environments. Journal of Sports Sciences, 35, 44-55. doi:10.1080/02640414.2016.1241422

Tracy, S. (2010). Qualitative quality: Eight 'big tent' criteria for excellent qualitative research. Qualitative Inquiry, 16, 837-851. doi:10.1177/1077800410383121

Weed, M. (2009). Research quality considerations for grounded theory research in sport \& exercise psychology. Psychology of Sport \& Exercise, 10, 502-510. doi:10.1016/j.psychsport.2009.02.007

Wimpenny, P., \& Gass, J. (2000). Interviewing in phenomenology and grounded theory: Is there a difference?. Journal of Advanced Nursing, 31, 1485-1492. doi:10.1046/j.1365-2648.2000.01431.x

Winterheld, H. A., \& Simpson, J. A. (2011). Seeking security or growth: A regulatory focus perspective on motivations in romantic relationships. Journal of Personality and Social Psychology, 101, 935-954. doi:10.1037/a0025012

Wolgemuth, J.R., Erdil-Moody, Z., Opsal, T., Cross, J.E., Kaanta, T., Dickmann, E.M., Colomer, S. (2015). Participants' experiences of the qualitative interview: Considering the importance of research paradigms. Qualitative Research, 15, 351372. doi: $10.1177 / 1468794114524222$ 
Table 1. Session plan for the workshop.

\begin{tabular}{|c|c|c|c|}
\hline Activity & Aim & What this will involve & Example probes \\
\hline $\begin{array}{l}\text { What demands do } \\
\text { you face in your } \\
\text { role? }\end{array}$ & $\begin{array}{l}\text { To explore the stressors } \\
\text { coaches and athletes face } \\
\text { in sport and understand } \\
\text { the importance of coping } \\
\text { with stressors in sport. }\end{array}$ & $\begin{array}{l}\text { In groups, participants will be asked to draw a } \\
\text { timeline and describe the demands faced by } \\
\text { coaches and athletes at particular points } \\
\text { within their season. }\end{array}$ & $\begin{array}{l}\text {-Are any of these shared demands within } \\
\text { the coach-athlete relationship? } \\
\text {-Who is there to support you? }\end{array}$ \\
\hline $\begin{array}{l}\text { What would you } \\
\text { do? }\end{array}$ & $\begin{array}{l}\text { To consider strategies } \\
\text { which can be applied } \\
\text { when managing a stressor } \\
\text { in the coach-athlete } \\
\text { relationship and } \\
\text { understand how to cope } \\
\text { with stressors in the } \\
\text { coach-athlete } \\
\text { relationship. }\end{array}$ & $\begin{array}{l}\text { Participants will be given scenarios and asked } \\
\text { to consider how they would manage the } \\
\text { situation from their position. }\end{array}$ & $\begin{array}{l}\text {-What actions would you suggest the } \\
\text { athlete and coach take? } \\
\text {-Whose stress is this? } \\
\text {-What factors may influence your decision } \\
\text { making? } \\
\text {-What levels of communication are } \\
\text { required? } \\
\text { - Have you experienced this situation? If } \\
\text { so, how did you react? }\end{array}$ \\
\hline $\begin{array}{l}\text { What is dyadic } \\
\text { coping? }\end{array}$ & $\begin{array}{l}\text { To learn about a concept } \\
\text { that explains } \\
\text { interpersonal coping in } \\
\text { coach-athlete } \\
\text { relationships. }\end{array}$ & $\begin{array}{l}\text { Participants will be asked to listen to the } \\
\text { recordings and read the transcripts (case } \\
\text { studies) provided to them. In small groups } \\
\text { ( } \mathrm{n}=4 / 5 \text { ) they will be asked to discuss the } \\
\text { concept of dyadic coping. Following this, } \\
\text { participants will be provided with a } \\
\text { definition and an outline of dyadic coping. }\end{array}$ & $\begin{array}{l}\text {-To what extent do you experience this in } \\
\text { your coach-athlete relationship? }\end{array}$ \\
\hline $\begin{array}{l}\text { Constructing a } \\
\text { theory of dyadic } \\
\text { coping. }\end{array}$ & $\begin{array}{l}\text { To critically discuss and } \\
\text { provide feedback on a } \\
\text { theory that explains } \\
\text { dyadic coping in coach- } \\
\text { athlete relationships. }\end{array}$ & $\begin{array}{l}\text { Participants will be asked to comment on the } \\
\text { theory and provide a critical dialogue around } \\
\text { the constructed categories. }\end{array}$ & $\begin{array}{l}\text {-Does this theory make sense in relation to } \\
\text { your understanding and experiences of } \\
\text { coping in the coach-athlete relationship? } \\
\text {-Are there any refinements you would } \\
\text { make to various parts of this theory? } \\
\text {-Do you have any further comments? }\end{array}$ \\
\hline
\end{tabular}




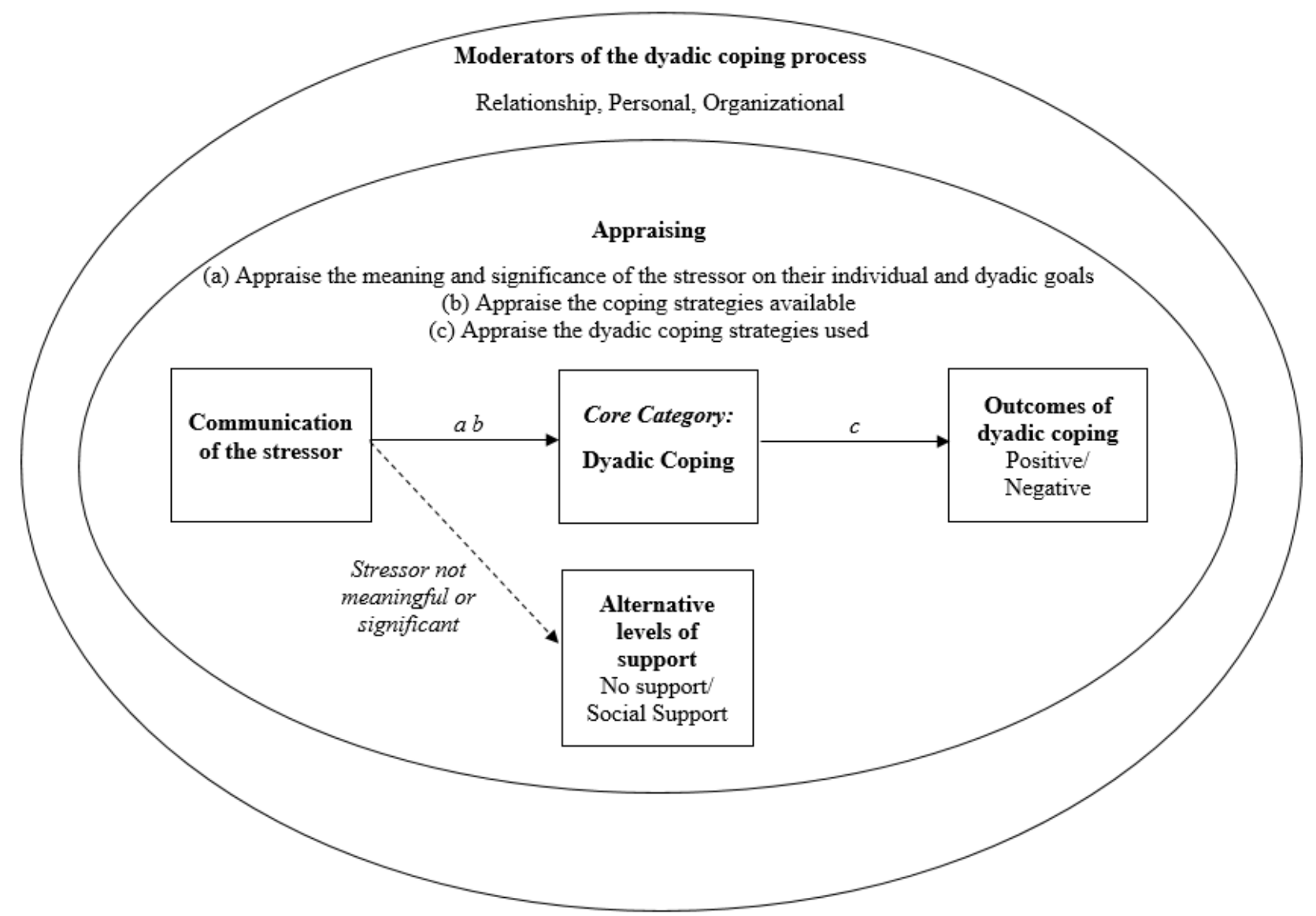

Figure 1. A substantive theory of dyadic coping in coach-athlete relationships 